\title{
A Receiver-Controlled Coupler for Multiple Output Wireless Power Transfer Applications
}

\author{
Chen, Xu; Yu, Shengbao; Zhang, Zhe
}

Published in:

IEEE Transactions on Circuits and Systems Part 1: Regular Papers

Link to article, DOI:

10.1109/TCSI.2019.2924949

Publication date:

2019

Document Version

Peer reviewed version

Link back to DTU Orbit

Citation $(A P A)$ :

Chen, X., Yu, S., \& Zhang, Z. (2019). A Receiver-Controlled Coupler for Multiple Output Wireless Power Transfer Applications. IEEE Transactions on Circuits and Systems Part 1: Regular Papers, 66(11), 4542-4552. https://doi.org/10.1109/TCSI.2019.2924949

\section{General rights}

Copyright and moral rights for the publications made accessible in the public portal are retained by the authors and/or other copyright owners and it is a condition of accessing publications that users recognise and abide by the legal requirements associated with these rights.

- Users may download and print one copy of any publication from the public portal for the purpose of private study or research.

- You may not further distribute the material or use it for any profit-making activity or commercial gain

- You may freely distribute the URL identifying the publication in the public portal 


\title{
A Receiver-Controlled Coupler for Multiple Output Wireless Power Transfer Applications
}

\author{
Xu. Chen, Student Member, IEEE, Shengbao. Yu, and Zhe. Zhang, Member, IEEE
}

\begin{abstract}
Multiple output wireless power transfer (WPT) system has great potential to be used in applications where multiple receivers need to be powered simultaneously, including wireless office table, logistic sorting robots and magnetic resonant imaging (MRI) equipment. For the sake of reducing no-load losses and avoiding leakage magnetic fields, it is desirable to only switch on those transmitter coils that are covered by receivers and switch off the rests. To realize this, however, bidirectional power switches, sensors and control logic are needed, which is expensive, bloated and lossy. This paper proposed a novel receiver-controlled coupler (RC-Coupler) that can realize switching on/off of transmitter coils without using bidirectional switches, sensors and control. The structure, design considerations and leakage fields of the proposed RC-coupler are researched, and its feasibility has been confirmed with a GaN based $120 \mathrm{~W}, 6.78 \mathrm{MHz}$ prototype. A power density of $2.78 \mathrm{~W} / \mathrm{cm}^{3}$ is reached benefit from the receiver-controlled characteristics.
\end{abstract}

Index Terms-wireless power transfer (WPT), multiple output, leakage magnetic field, efficiency.

\section{INTRODUCTION}

$\mathrm{W}$ ith the improvement of power electronics technology and circuit theory, wireless power transfer becomes a fast developing technology and is being used in many aspects of our life, such as electrical vehicles, railway transportation [1] - [3], implant devices [4] - [6] and consumer electronic products [7]. A bright prospect is in front of this technology and it is promising to be used in more and more applications in the future.

Currently, the single input single output (SISO) wireless power transfer has been well researched and commercialized because of its relatively simpler system configuration and control strategy. However, the SISO wireless power transfer is not enough to meet the charging requirement of more and more electronic devices in everyday life considering cost, convenience, etc. Take a typical office table for example, normally there might be a table lamp, a laptop, a monitor, a cell phone, a wireless key board, a wireless mouse and a humidifier on it. If all these devices are charged in a SISO way, the table will still be full of cables as every SISO wireless charger need to be connected to the grid through independent power cable. Single input multiple output (SIMO) [8] wireless power transfer

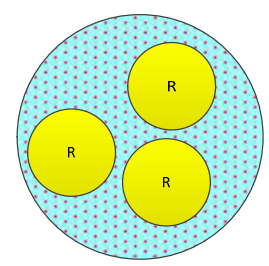

(a)

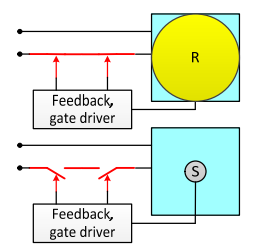

(c)

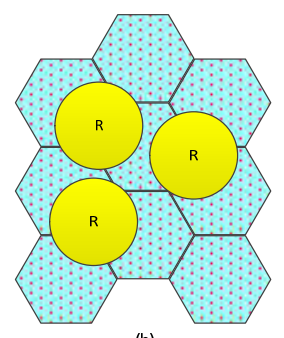

(b)

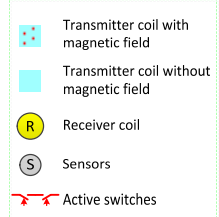

7. A Active switches
Fig. 1. Three system configurations to realize multiple output wireless power transfer, (a) Big transmitter coil, (b) UCBCP and (c) Active switches with feedback control.

system is a better solution for such kind of application and is attracting more and more research and commercial interests recently. For example, a multiple output wireless charging table was demonstrated by EPC in 2016 [9]. Another application of multiple output wireless power transfer is logistic sorting system, where hundreds of automatic guided vehicles (AGV) are used for sorting logistic packages. Besides, multiple output wireless power transfer can also be used in industrial applications. Grant A. Covic and John T. Boys et.al made a significant contribution in track-type wireless power transfer topology. The primary coil is a long track, where multiple receivers move along and receive power from the track. It is successfully used in clean room [10].

To realize multiple output wireless power transfer, typically either a big transmitter coil or a small transmitter coil arrays are needed, as shown in Fig. 1(a) and (b). For the big coil configuration, the number of receivers is limited, and the control freedom is also limited, any modification of primary coil will affect all the receivers. Leakage magnetic field problem are series since the transmitter coil can't be perfectly covered by receivers. It is also hard to realize high system efficiency because of the weak coupling between transmitter coil and each receiver coil. S. Y. Ron Hui et.al proposed a small transmitter coil array solution called Universal Contactless Battery Charging Platform (UCBCP), which uses three-layer 
hexagonal coils connected in series to build a uniform magnetic field on the planar surface so that electronic devices can be charged everywhere on the plane [11] - [15]. However, those coils not covered by the receiver are also active with current and high frequency leakage magnetic field, which may heat up metal objects like coins or keys around them. A potential harmful effect on human exposed to the leakage magnetic field also prevent this technology from been widely used. Meanwhile, the extra coil loss is also a drawback of series connected coil arrays since all the coils are excited at the same time even if only one transmitter coil is used to transfer power.

For the sake of reducing no-load losses and avoiding leakage magnetic field, it is desirable to only switch on those transmitter coils that are transferring power to the receiver and switch off the rests. To realize this, bidirectional switches are introduced. These bidirectional switches are series connected to each transmitter coil and sensors are used to detect the existence of receivers [16], which is used in magnetic resonant imaging (MRI) equipment. To avoid interacting with the T0 and T1 fields of MRI, which will cause distortion of the imaging system, a control logic is used to control the bidirectional switches based on the feedback of sensors to ensure only the specific transmitter coil under the receiver is switched on and the rest is off, as shown in Fig. 1(c).

The drawbacks of using bidirectional switches are obvious, the system becomes expensive and bloated because of these sensors, bidirectional switches, drivers and control circuits. In [16], except for the inverter, an extra $106 \mathrm{~mm} \times 111 \mathrm{~mm}$ PCB board with twelve power switches are used to switch on/off the three transmitter coils with $25 \mathrm{~W}$ output. Moreover, these bidirectional switches also cause conduction losses which will lower the system efficiency.

To keep the selective switching feature of transmitter coils while avoiding the complex bidirectional switches, researchers have tried to utilize the parasitic parameters between the transmitter and the receiver to build a switch. Reference [17] presented a method to achieve bounded spatial freedom using flux-guide saturation for flux delivery to one or more secondary coils for contactless inductive power transfer. The transmitter coils are covered by ferrite and by using the nonlinearity feature

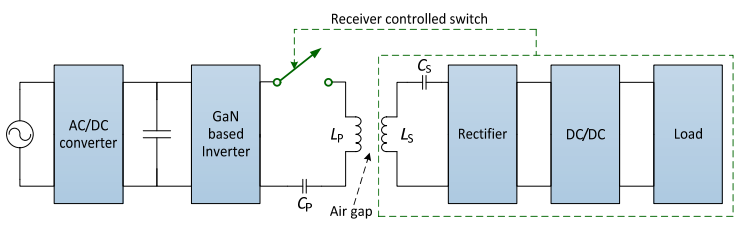

Fig. 2. Receiver controlled wireless power transfer concept.

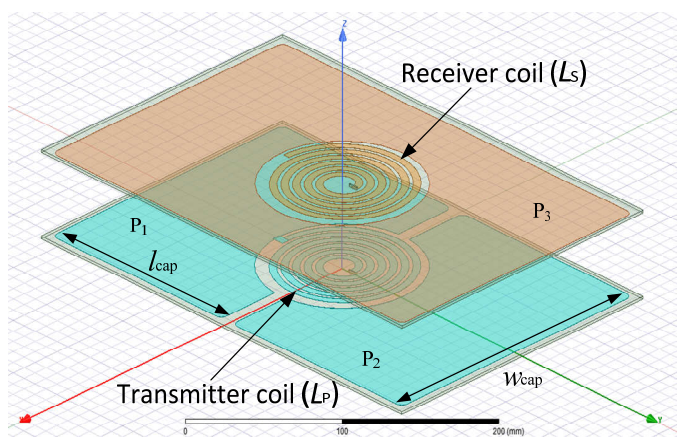

(a)

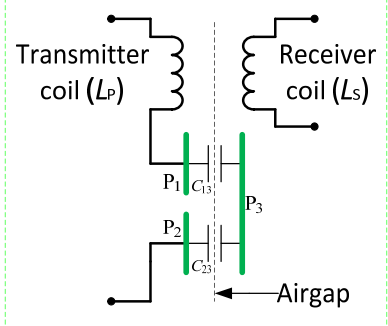

(b)

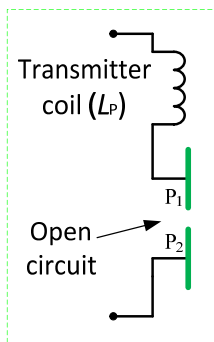

(c)
Fig. 3. (a) Structure of proposed RC-Coupler, (b) its equivalent circuit with receiver pad and (c) without receiver pad.

of ferrite materials, the primary flux is shielded within the ferrite when no receiver is on top of the transmitter coil. If a transmitter coil is covered by a receiver, a flux path is 'opened up' from transmitter coil to the receiver coil by selectively letting the ferrite to saturate using biased DC current. This method solved the leakage magnetic field problem, but the introducing of ferrite causes more loss in addition to the coil loss problem that is not solved by this method.

To solve the above-mentioned leakage magnetic and low

TABLE I

COMPARISON OF DIFFERENT MULTIPLE OUTPUT WIRELESS POWER TRANSFER SOLUTION

\begin{tabular}{|c|c|c|c|c|c|c|c|c|}
\hline Ref & Power & Efficiency & $\begin{array}{l}\text { Tx and } R x \text { coil } \\
\text { size }\end{array}$ & $\begin{array}{l}\text { Power density } \\
\text { (converter) }\end{array}$ & $\begin{array}{l}\text { Position } \\
\text { free? }\end{array}$ & Number of Components & $\begin{array}{l}\text { Leakage } \\
\text { magnetic } \\
\text { field }\end{array}$ & $\begin{array}{l}\text { Number } \\
\text { of } \\
\text { receivers }\end{array}$ \\
\hline [10] & $<1 \mathrm{~W}$ & $89.82 \%$ & $\begin{array}{l}T \times 6361.7 \mathrm{~mm}^{2} \\
\operatorname{Rx} 433.7 \mathrm{~mm}^{2}\end{array}$ & 1 & Yes & 1 & Yes & 3 \\
\hline [11-15] & $1.58 \mathrm{~W}$ & 1 & $\begin{array}{l}\text { Tx } 10800 \mathrm{~mm}^{2} \\
\text { ( } 21 \text { coils) } \\
\operatorname{Rx} 1194.6 \mathrm{~mm}^{2} \\
\end{array}$ & 1 & Yes & $\begin{array}{l}\text { Commercial RF } \\
\text { amplifier }\end{array}$ & Yes & 1 \\
\hline [16] & $21.6 \mathrm{~W}$ & $62.97 \%$ & $\begin{array}{l}\text { Tx } 120000 \mathrm{~mm}^{2}, \\
3 \text { coils } \\
\text { Rx } 40000 \mathrm{~mm}^{2}, \\
1 \text { coil }\end{array}$ & $\begin{array}{l}50 \mathrm{~mm} \times 50 \mathrm{~mm} \times 15 \\
\mathrm{~mm} \text { inverter and } \\
111 \times 106 \mathrm{~mm}^{2} \mathrm{RF} \\
\text { switch matrix }\end{array}$ & Yes & $\begin{array}{l}\text { Inverter + } 12 \text { MEMS RF } \\
\text { switches (14 switches) }\end{array}$ & no & 1 \\
\hline [17] & $0.48 \mathrm{~W}$ & $43.8 \%$ & $\begin{array}{l}\text { Tx } 5700 \mathrm{~mm}^{2} \\
\operatorname{Rx} 1066 \mathrm{~mm}^{2}\end{array}$ & 1 & Yes & $\begin{array}{l}\text { Inverter + extra DC bias } \\
\text { circuit ( }>2 \text { switches) }\end{array}$ & No & 1 \\
\hline $\begin{array}{l}\text { This } \\
\text { paper }\end{array}$ & $120 W$ & $81.42 \%$ & $\begin{array}{l}\mathrm{Tx} 60000 \mathrm{~mm}^{2} \\
\operatorname{Rx} 60000 \mathrm{~mm}^{2}\end{array}$ & $\begin{array}{l}30 \mathrm{~mm} \times 60 \mathrm{~mm} \times 30 \\
\mathrm{~mm}\end{array}$ & Yes & Inverter (2 switches) & No & 3 \\
\hline
\end{tabular}


efficiency problem of a multiple output wireless power transfer system, a receiver-controlled wireless power transfer concept, as shown in Fig. 2, is proposed in this paper. A switch is designed in series with each transmitter coil and this switch is controlled by the receiver. When a receiver is put on top of a transmitter coil, the switch of that specific transmitter coil is activated. Power is wirelessly transferred through that transmitter coil to the receiver. When the receiver is moved away, this switch is automatically deactivated, and the primary transmitter coil becomes open circuit, no extra current or leakage magnetic fields are generated, meanwhile, the remaining transmitter coils are not affected. More specifically, a novel receiver-controlled coupler (RC-Coupler) that utilizing the parasitic capacitances between the transmitter and receiver as the receiver-controlled switch is proposed and evaluated in this paper. Table I gives a detailed comparison of the abovementioned different multiple output wireless power transfer solutions in terms of power, efficiency, power density, etc. Compared with uniform primary field configuration, the leakage magnetic field is eliminated. The system efficiency is also increased since there are no currents in those uncovered transmitter coils. Compared with bidirectional switch configuration, the proposed RC-Coupler is superior in terms of volume, cost and control complexity.

This paper is organized as follows. The structure, work principle and a detailed analysis of facts that affect the coupling capacitance of the RC-Coupler is explained in section II. A simplified system design guideline is given in section III. The leakage magnetic field around the proposed RC-Coupler are evaluated in section IV by FEM simulation, followed by experimental testing and validation in section V. A $120 \mathrm{~W}$, $6.78 \mathrm{MHz}$ receiver-controlled wireless power transfer prototype with three outputs is built to validate the analysis and calculation. Finally, conclusions are given in section VI.

\section{THE PROPOSED COUPLER}

\section{A. Coupler description}

The RC-Coupler proposed in this paper is shown as Fig. 3(a). The key idea is to replace primary compensation capacitor with separable parallel plate capacitor (PP-Cap). The coupler composes two separable PCB boards, namely the primary pad and secondary pad. The primary pad composes two metal plates $\left(\mathrm{P}_{1}\right.$ and $\left.\mathrm{P}_{2}\right)$ and a coil $\left(L_{\mathrm{p}}\right)$. The secondary pad composes one metal plate $\left(\mathrm{P}_{3}\right)$ and a coil $\left(L_{\mathrm{s}}\right)$. The primary pad is connected to the primary inverter as a part of the transmitter and the secondary pad is connected to receiver. The equivalent circuit of the proposed coupler is shown in Fig. $3(\mathrm{~b})$. $L_{\mathrm{p}}$ represents the transmitter coil and $L_{s}$ represents the receiver coil. A separable PP-Cap $C_{13}$ is formed by $\mathrm{P}_{1}$ and $\mathrm{P}_{3}$. Similarly, another separable PP-Cap $C_{23}$ is formed by $\mathrm{P}_{2}$ and $\mathrm{P}_{3}$. Since the area of $\mathrm{P}_{1}$ is the same as that of $\mathrm{P}_{2}, C_{13}$ equals to $C_{23}$ and they are series connected by $\mathrm{P}_{3}$. Note that $\mathrm{P}_{3}$ has no electrical connection with the receiver side circuit. Define the equivalent series capacitance of $C_{13}$ and $C_{23}$ as $C_{\mathrm{pp} i}$, where the index $i$ represent the $i_{\text {th }}$ RC-Coupler in a multiple output wireless power transfer system. $C_{\mathrm{ppi}}$ is used to replace the primary resonant capacitor.

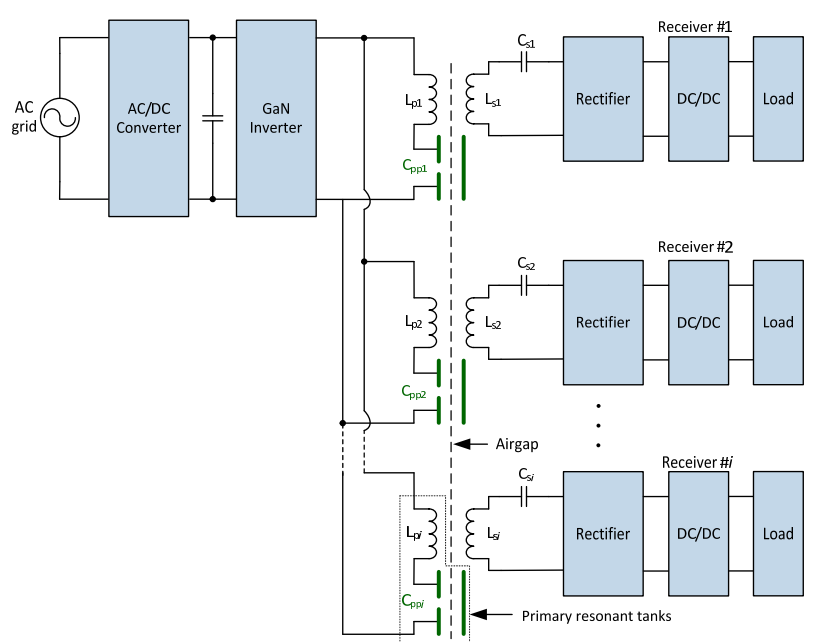

Fig. 4. A multiple output wireless power transfer topology using proposed RC-Coupler.

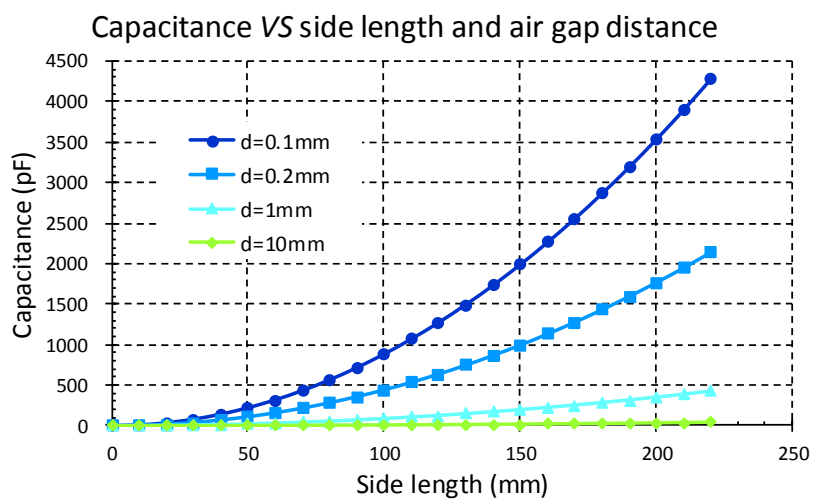

Fig. 5. Capacitance of Non-touched PP-Cap with different side length and air gap distance.
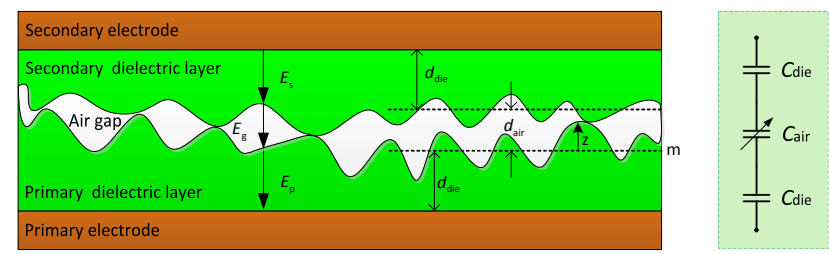

Fig. 6. Cross-sectional structure of PP-Cap and its equivalent circuit.

Capacitance VS pressure and dielectric materials

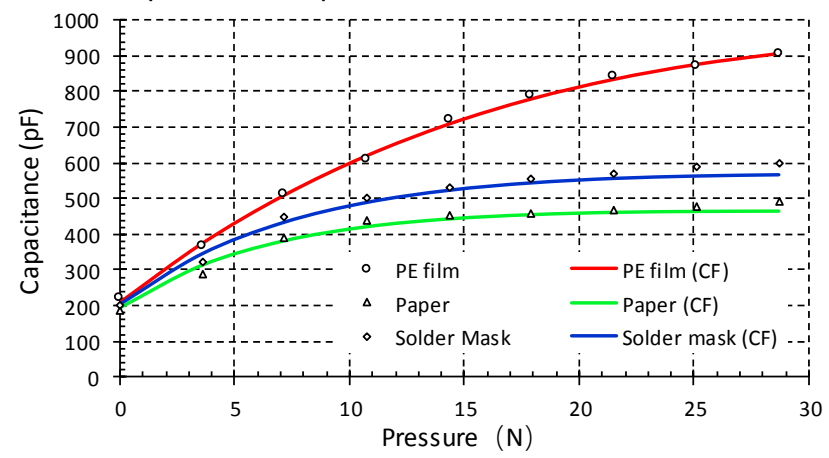

Fig. 7. Measured capacitance of different dielectric materials and pressure.

A unique characteristic is brought by doing this. Since the $C_{\mathrm{pp} i}$ is formed by both transmitter and receiver, and it is series 
connected with the primary coil. Once the receiver (including $\mathrm{P}_{3}$ ) is moved away from the transmitter coil $L_{\mathrm{p} i}$, as shown in Fig. $3(\mathrm{c})$, the two electrodes of capacitor $C_{13}$ and $C_{23}$ are separated and the primary side resonant tank becomes open circuit. Even the primary inverter is working, and the rest of the primary coils are transferring power, there is no current in this uncovered coil $L_{\mathrm{p} i}$.

A multiple output wireless power transfer topology using the proposed RC-Coupler is shown as Fig. 4. The primary side of the topology comprises AC/DC converter, GaN based high frequency inverter, primary coils $\left(L_{\mathrm{p} 1}-L_{\mathrm{p} i}\right)$ and primary resonant capacitors $\left(C_{\mathrm{pp} 1}-C_{\mathrm{pp} i}\right)$. At the secondary side, each receiver has its own receiver coil $\left(L_{\mathrm{s} i}\right)$ and resonant capacitor $\left(C_{\mathrm{s} i}\right)$ as well as rectifier circuit and a $\mathrm{DC} / \mathrm{DC}$ converter to regulate appropriate voltage for different electronic devices.

\section{B. Design of separable PP-Cap}

A PP-Cap can be divided into non-touched PP-Cap and touched PP-Cap, where non-touched means a visible air gap exists between two electrodes. For non-touched PP-Cap, the capacitance is determined by formula (1)

$$
C=\frac{\varepsilon_{0} S}{d}=\frac{\varepsilon_{0} L_{\mathrm{s}}^{2}}{d} .
$$

The coupling capacitance with different air gap distance $d$ and side length $L_{\mathrm{s}}$ is depicted in Fig. 5. When $d$ is larger than $1 \mathrm{~mm}$, the coupling capacitance increases slowly with $L_{\mathrm{s}}$, where the distance of air gap $d$ dominates the coupling capacitance. When $d$ is less than $1 \mathrm{~mm}$, the side length $L_{\mathrm{s}}$ makes more influence on the capacitance. As summarized in [18], most research of capacitive power transfer focus on air gap less than $1 \mathrm{~mm}$, the main reason is that the coupling capacitance is too low for large air gap capacitors considering their volume.

For touched PP-cap, however, the coupling capacitance can be increased since the air gap between the two electrodes is minimized. The cross-sectional structure of the $C_{13}$ in Fig. 3 is illustrated in Fig. 6. It consists of five layers, including two capacitor electrode layers, two dielectric layers, and an air-gap layer. The capacitor plate layer is made by metal, e.g. copper or aluminum sheets. There are many materials that can be used for the dielectric layer. In this paper, several materials with similar thickness as shown in Table I are studied. As shown in Fig. 6, although there is no visible air gap layer in touched PP-Cap, some equivalent air gap layers still exist. Because in molecular level the microscopic surface of any material cannot be absolutely smooth. Surface roughness $R_{\mathrm{a}}$ is a parameter used for expressing the unevenness of a surface [19],

$$
R_{\mathrm{a}}=\frac{1}{L} \int_{0}^{L}|z-m| d x
$$

Where $|z-m|$ is the absolute offset relative to a reference plane and the reference plane is defined such that the area above the reference plane is equal to the area under the reference plane, see Fig. 6. For two touched surfaces with surface roughness $R_{\mathrm{a} \_\mathrm{p}}$ and $R_{\mathrm{a} \_}$s, the equivalent air gap layer thickness is

$$
d_{\text {air }}=R_{\mathrm{a} \_\mathrm{p}_{\mathrm{p}}}+R_{\mathrm{a} \_\mathrm{s}_{\mathrm{s}}} \text {. }
$$

TABLE II

PARAMETERS OF DIELECTRIC MATERIALS

\begin{tabular}{cccc}
\hline \hline Materials & $\begin{array}{c}\text { Dielectric } \\
\text { constant }\end{array}$ & Thickness & $\begin{array}{c}\text { Surface } \\
\text { roughness }\end{array}$ \\
\hline Solder Mask & 3.5 & $70 \mu \mathrm{m}$ & $1 \mu \mathrm{m}$ \\
PE film & 2.25 & $80 \mu \mathrm{m}$ & $0.1 \mu \mathrm{m}$ \\
Paper & 1.4 & $88 \mu \mathrm{m}$ & $5 \mu \mathrm{m}$ \\
\hline \hline
\end{tabular}

TABLE III

PARAMETERS OF CURVE FITTING

\begin{tabular}{ccccc}
\hline \hline Materials & $\mathrm{a}$ & $\mathrm{b}$ & $\mathrm{c}$ & $\mathrm{d}$ \\
\hline Solder Mask & 170.31 & 0.0012 & -111.94 & -0.1271 \\
PE film & 817.33 & -0.0096 & -724 & 0.0420 \\
Paper & 347.36 & 0.0012 & -209.93 & -0.1504 \\
\hline \hline
\end{tabular}

For simplicity, in this paper, the dielectric material as well as the surface roughness of the two dielectric layers are kept the same. Based on Fig. 6, a PP-Cap can be equivalent as the series value of three capacitors

$$
\begin{gathered}
C_{\mathrm{pp}}=\frac{1}{\frac{1}{C_{\text {die_p }}}+\frac{1}{C_{\text {air }}}+\frac{1}{C_{\text {die_s }_{-}}}} \\
C_{\text {die_p }}=C_{\text {die_s }_{-}}=\frac{\varepsilon_{\mathrm{r}} \varepsilon_{0} L^{2}}{d_{\text {die }}} \\
C_{\text {air }}=\frac{\varepsilon_{0} L^{2}}{d_{\text {air }}} .
\end{gathered}
$$

Except for side length $L_{\mathrm{s}}$, the coupling capacitance of touched PP-Cap is also sensitive to the dielectric constant of dielectric layer $\varepsilon_{r}$, the surface roughness $R_{a}$ of the dielectric layer and the pressure added to the capacitor electrode. The side length is usually determined by the geometry of specific application. Surface roughness $R$ a and pressure $F$ is not directly included in (4) but they will affect the air-gap layer thickness $d_{\mathrm{b}}$ in Fig. 6. Lower $R_{\mathrm{a}}$ or higher $P$ will lead to thinner air-gap layer and thus higher capacitance.

The coupling capacitance of PP-Cap using dielectric materials in Table I with a side length of $100 \mathrm{~mm}$ are measured and shown in Fig. 7. It can be observed from Fig. 7 that the coupling capacitance increase fast when pressure is low and tend to saturate at certain pressure level. This trend can be expressed using the following two-order exponential function, where $F$ is the pressure added to the capacitor electrode

$$
d_{\text {air }}^{\prime}=R_{\mathrm{a}}\left(a \cdot e^{-b \cdot F}+c \cdot e^{-d \cdot F}\right) .
$$

Curve fitting Fig. 7 with equations (4)-(7), the corresponding coefficients for different materials can be obtained as shown in Table II. For touched PP-Cap, adding pressure or reduce surface roughness can significantly increase the capacitance. The resonant frequency of a series compensated WPT system is determined by resonant capacitance and coil inductance. To comply with the A4WP [20] and ISM standards [21], the switching frequency of the inverter is set as $6.78 \mathrm{MHz}$. Once the 
frequency is fixed, a higher capacitance requires lower inductance, and vice versa. In this paper, a $20 \mathrm{~cm}$ by $30 \mathrm{~cm}$ coupler is designed for a 14-inches laptop with bottom area of $22 \mathrm{~cm}$ by $33 \mathrm{~cm}$. The solder mask layers of PCB board are used as dielectric layers and the pressure between the capacitor electrode is the weight of a laptop $(\sim 2.25 \mathrm{~kg})$. As shown in Table III, based on (3)-(7) and Fig. 7, the calculated total capacitance $C_{\mathrm{pp}}$ is $659.69 \mathrm{pF}$ and the measured capacitance is $610 \mathrm{pF}$. The error between calculation and measurement result is $8.14 \%$.

This may be caused by the distortion of capacitor plate and thickness error of solder mask layer during manufacturing.

For some applications like laptop, AGV and MRI, the coupler area is not a big issue because their bottom side length is normally larger than $200 \mathrm{~mm}$. Thus, the bottom area is big enough to build a separable capacitor $C_{\mathrm{pp}}$ capable of serving as primary side resonant capacitor. On the other hand, the power density of transmitter and receiver converters should be maximized since it need to be imbedded into electronic devices. By using the separable capacitor $C_{\mathrm{pp}}$ as receiver-controlled switch, the bidirectional power switches and its control circuits in [16] can be saved while keeping the system performance (only the coils under receiver are activated) unchanged. This will reduce the volume of the primary side circuits.

\section{Design of coils} [22],

The inductance of a PCB based coil can be determined by

$$
L=\frac{\mu n^{2} d_{\text {avg }} c_{1}}{2}\left(\ln \left(c_{2} / \rho\right)+c_{3} \rho+c_{4} \rho^{2}\right),
$$

Where $n$ is the number of turns, $c_{\mathrm{i}}$ are geometry dependent parameters, and for circular coil $c_{1}$ is $1.00, c_{2}$ is $2.46, c_{3}$ equals to zero and $c_{4}$ is 0.20 . Average diameter $d_{\text {avg }}$ is defined as $0.5\left(d_{\text {out }}+d_{\text {in }}\right)$ and filling factor $\rho$ is defined as $\left(d_{\text {out }}-d_{\text {in }}\right) /\left(d_{\text {out }}+d_{\text {in }}\right)$. The physical dimension of different coils is given in Fig. 8. In this paper, the transmitter and receiver coil parameters are listed in table III.

\section{System Design}

Some specifications are made before the system design. Define the receiver voltage as $V_{\mathrm{r}}$ and receiver power as $P_{\mathrm{r}}$. To obtain a stable receiver voltage, a Buck DC/DC converter is used to regulate the output voltage. The equivalent load resistance seen from the input of DC/DC can be calculated as

$$
R_{\mathrm{dc}}=\frac{P_{\mathrm{r}} \cdot D}{\eta_{\mathrm{dc}} \cdot V_{\mathrm{r}}}
$$

Where $D$ is the duty cycle of the DC/DC converter. Using fundamental approximation [23], the rectifier circuit, DC/DC and receiver can be simplified as an equivalent $\mathrm{AC}$ resistance

$$
R_{\mathrm{ac}}=\frac{8}{\pi^{2}} \cdot R_{\mathrm{dc}} \text {. }
$$

Similarly, the primary AC/DC converter and half-bridge inverter can also be simplified as a voltage source $V_{\text {ac }}$ with its frequency equals to the switching frequency of the inverter [24]

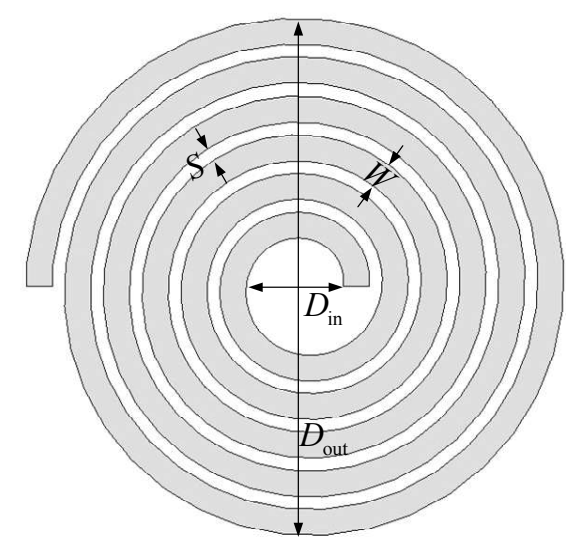

Fig. 8. Layout and dimension of transmitter and receiver coils.

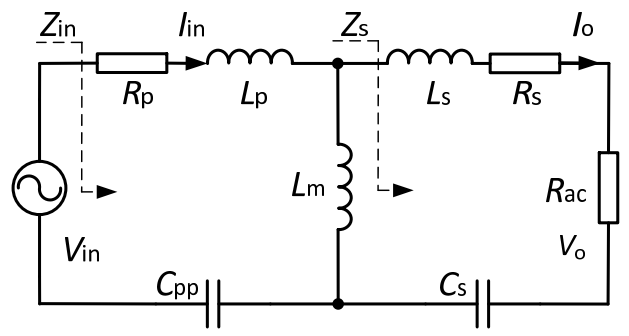

Fig. 9. Equivalent circuit of RC-Coupler based WPT.

TABLE IV

PARAMETERS OF CAPACITORS AND COILS FOR RC-COUPLER

\begin{tabular}{cccc}
\hline \hline Symbol & Value & Symbol & Value \\
\hline$l_{\text {cap }}$ & $100 \mathrm{~mm}$ & $S$ & $2.5 \mathrm{~mm}$ \\
$w_{\text {cap }}$ & $200 \mathrm{~mm}$ & $W$ & $5 \mathrm{~mm}$ \\
$d_{\text {die }}$ & $35 \mu \mathrm{m}$ & $D_{\text {out }}$ & $85 \mathrm{~mm}$ \\
$F$ & $22.05 \mathrm{~N}$ & Turns & 5.5 \\
\hline \hline
\end{tabular}

$$
V_{\mathrm{ac}}=\frac{\sqrt{2}}{\pi} V_{\mathrm{dc}} \sin (2 \pi f \cdot t)
$$

where $V_{\mathrm{dc}}$ represents the DC-link voltage of inverter. Thus, the system can be simplified as Fig. 9. The transmitter coil and receiver coil can be handled as a loosely coupled transformer and it can be modeled as a T-type equivalent circuit including primary side leakage inductance $L_{\mathrm{p}}$, secondary side leakage inductance $L_{\mathrm{s}}$ and magnetization inductance $L_{\mathrm{m}}$. There are two resonant tanks for each RC-Coupler, the primary resonant tank formed by $L_{\mathrm{p}}, C_{\mathrm{pp}}$ and the secondary resonant tank formed by $L_{\mathrm{s}}, C_{\mathrm{s}}$, and their resonant frequencies are

$$
f_{\mathrm{p}}=\frac{1}{2 \pi \sqrt{L_{\mathrm{p}} C_{\mathrm{pp}}}}, f_{\mathrm{s}}=\frac{1}{2 \pi \sqrt{L_{\mathrm{s}} C_{\mathrm{s}}}} .
$$

Here, the primary resonant frequency $f_{\mathrm{p}}$ is designed equal to the secondary resonant frequency $f_{\mathrm{s}}$. The impedance $Z_{\mathrm{s}}$ seen from the magnetizing inductor to the receiver is

$$
Z_{\mathrm{s}}=j \omega L_{\mathrm{s}}+\frac{1}{j \omega C_{\mathrm{s}}}+R_{\mathrm{ac}}+R_{\mathrm{s}}
$$

The total impedance $Z$ in seen from $V_{\text {in }}$ is 


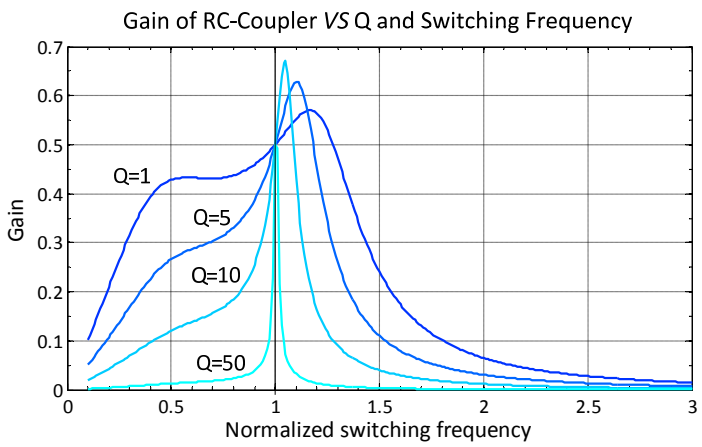

Fig. 10. Gain of RC-Coupler as a function of switching frequency and characteristic impedance.

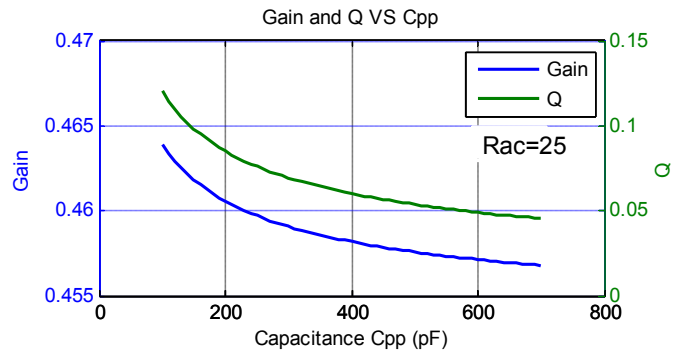

(a)

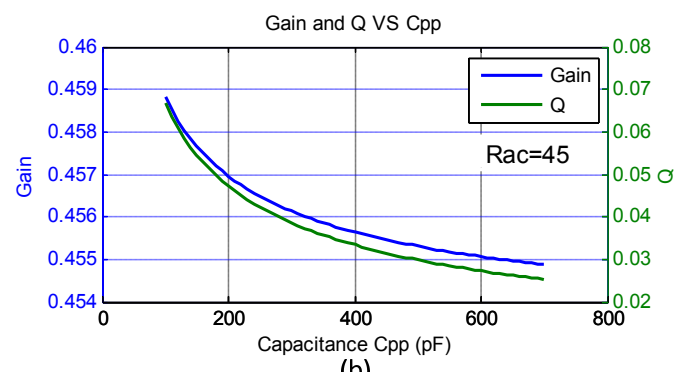

(b)

Fig. 11. Gain of RC-Coupler versus $C_{\mathrm{pp}}$ and $R_{\mathrm{ac}}$.

$$
Z_{\text {in }}=j \omega L_{\mathrm{p}}+\frac{1}{j \omega C_{\mathrm{pp}}}+R_{\mathrm{p}}+j \omega L_{\mathrm{m}} \mathrm{P} Z_{\mathrm{s}} .
$$

Similar to other resonant converter, the output voltage can be controlled by varying inverter frequency or varying input DC voltage, varying duty cycle is not the best option since it will make the inverter lost soft switching feature. The output voltage is also dependent on the gain of the resonant tank. Thus, the gain of RC-Coupler is derived at first. The gain of RC-Coupler can be written as

$$
\begin{aligned}
G(\omega) & =\frac{V_{\mathrm{o}}}{V_{\mathrm{in}}} \\
& =\frac{\frac{L_{\mathrm{m}} \cdot Z_{\mathrm{s}}}{L_{\mathrm{m}}+Z_{\mathrm{s}}}}{j \omega L_{\mathrm{p}}+\frac{1}{j \omega C_{\mathrm{pp}}}+R_{\mathrm{p}}+\frac{L_{\mathrm{m}} \cdot Z_{\mathrm{s}}}{L_{\mathrm{m}}+Z_{\mathrm{s}}}} \cdot \frac{R_{\mathrm{ac}}}{Z_{\mathrm{s}}} .
\end{aligned}
$$

To facilitate analysis, four factors are introduced:

1) Normalized working frequency $f_{\mathrm{n}}$,

$$
f_{\mathrm{n}}=f / f_{0} \text {. }
$$

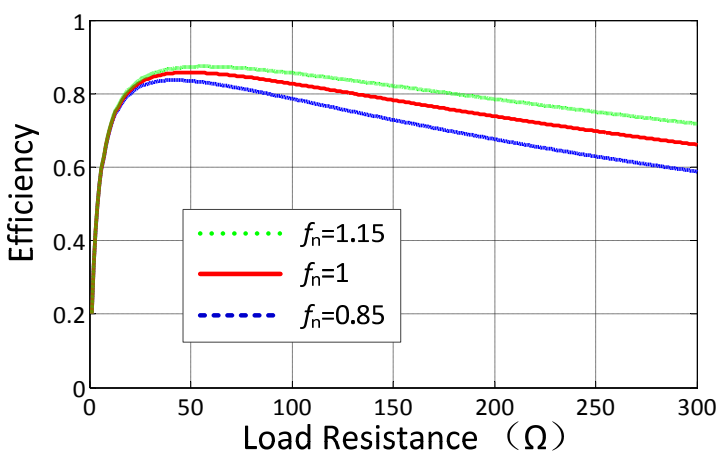

Fig. 12. Efficiency of RC-Coupler $\left(R_{\mathrm{p}}=R_{\mathrm{s}}=1 \Omega\right)$.

where $f$ is the primary voltage source frequency $(f=\omega / 2 \pi) . f_{0}$ is the resonant frequency of the resonant tank, which is determined by the value of inductor and capacitor. The normalized working frequency expresses the deviation of primary voltage source frequency compared with resonant frequency.

2) Characteristic impedance $Z$,

$$
Z=\sqrt{\frac{L_{\mathrm{p}}}{C_{\mathrm{pp}}}}=2 \pi f_{0} L_{\mathrm{p}}=\frac{1}{2 \pi f_{0} C_{\mathrm{pp}}} .
$$

3) Quality factor $Q$

$$
Q=\frac{Z}{R_{\mathrm{ac}}}=\frac{1}{R_{\mathrm{ac}}} \sqrt{\frac{L_{\mathrm{p}}}{C_{\mathrm{pp}}}} .
$$

4) Inductor ratio $\lambda$

$$
\lambda=L_{\mathrm{p}} / L_{\mathrm{s}}
$$

Substitute (16)-(19) into (15), the gain of RC-Coupler is,

$$
\left|G\left(\lambda, Q, f_{\mathrm{n}}\right)\right|=\frac{1}{2} \sqrt{\frac{a^{2}+b^{2}}{c^{2}+d^{2}}},
$$

Where

$$
\begin{gathered}
a=Q\left(1-f_{\mathrm{n}}^{2}\right) \\
b=f_{\mathrm{n}} \\
c=(\lambda+Q)\left(1-f_{\mathrm{n}}^{2}\right) \\
d=f_{\mathrm{n}}+f_{\mathrm{n}} Q+2 \lambda f_{\mathrm{n}} Q-\frac{\lambda Q}{f_{\mathrm{n}}}-f_{\mathrm{n}}^{3} Q(1+\lambda) .
\end{gathered}
$$

Fig. 10 shows the gain curves of RC-Coupler as a function of normalized switching frequency $f_{\mathrm{n}}$ and different $Q$ values. The gain of RC-Coupler shows a fixed gain point when normalized switching frequency equals to 1 . To ensure the soft switching of inverter, the input impedance of the RC-Coupler should be designed slightly inductive, which means the $f_{\mathrm{n}}$ is a little bit higher than 1. For a given switching frequency, according to (12) $C_{\mathrm{pp}}$ and $L_{\mathrm{p}}$ need to be designed to compensate each other so that the net impedance of the resonant tank is close to zero. Theoretically for any $C_{\mathrm{pp}}$, a $L_{\mathrm{p}}$ can be found to meet (12). However, as shown by (18), quality factor $Q$ is inversely proportional to $C_{\mathrm{pp}}{ }^{1 / 2}$. Increase $C_{\mathrm{pp}}$ gives a decrease in $Q$. And a lower $Q$ can ensure a more sable gain curve which is benefit for the controller design. According to (18) the $Q$ value is affected 


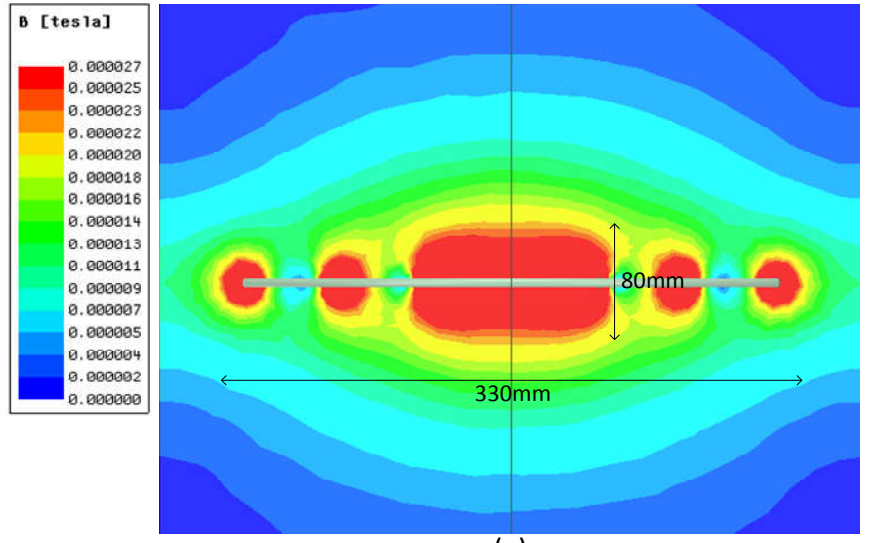

(a)

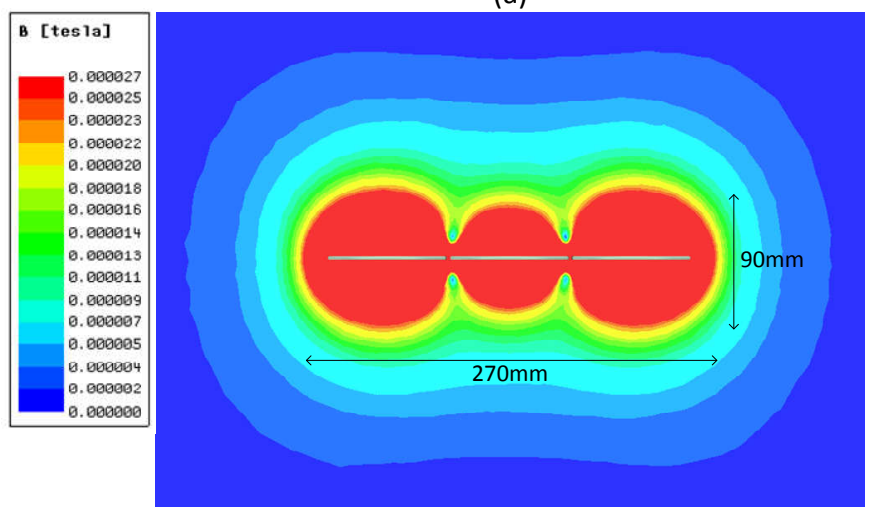

(b)

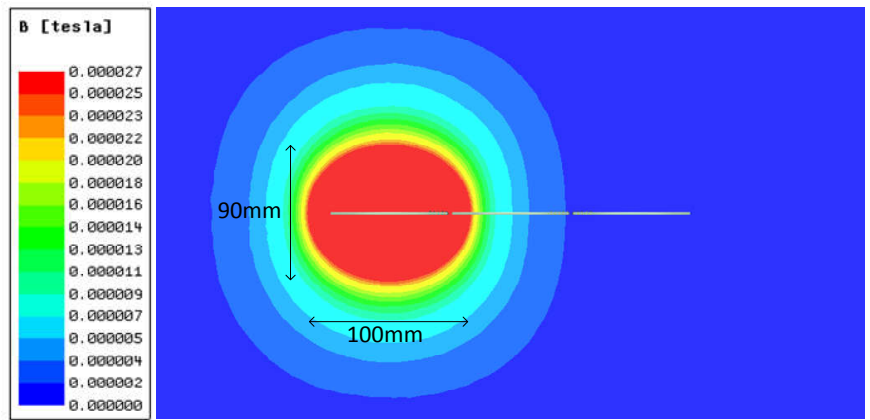

(c)

Fig. 13. Simulated magnetic fields around primary coil, (a) Big transmitter coil (b) UCBCP coil and (c) RC-Coupler.

by $R_{\text {ac. }}$ Substitute (4) into (18), the system gains versus different $C_{\mathrm{pp}}$ and $R_{\mathrm{ac}}$ is calculated and plotted as shown in Fig. 11.

In heavy load condition, $R_{\text {ac }}$ decrease results a high $Q$, which further cause a decrease in system gain. For light load condition, $Q$ and gain changes to the reverse direction. To keep a stable output voltage, either input voltage should be increased, or the primary voltage source frequency $f$ be adjusted toward the resonant frequency.

For a specific receiver with given load voltage and load power, to ensure the charging robustness at different conditions, the system should be designed to satisfy the load requirements at lowest gain condition. Thus, load change or coupling capacitance change will always lead to an increase in gain and rectified voltage, and this output voltage can then be regulated down to the specific load voltage. However, the highest voltage stress on the DC/DC should also be considered when gain increase
The input current and load current can be calculated as

$$
\begin{gathered}
I_{i n}=V_{s} / Z_{t} \\
I_{o}=I_{i n} \frac{j \omega L_{m}}{j \omega L_{m}+Z_{s}}
\end{gathered}
$$

Based on (25) and (26), the efficiency of the RC-Coupler can be calculated,

$$
\eta_{\mathrm{RC}-\text { Coupler }}=\frac{R_{\mathrm{ac}} I_{\mathrm{o}}^{2}}{R_{\mathrm{p}} I_{\mathrm{in}}^{2}+Z_{\mathrm{s}} I_{\mathrm{o}}^{2}}
$$

which is a function of all the passive components in Fig. 9. Using complex arithmetic, the efficiency of RC-Coupler with different loads and normalized frequency is shown as Fig. 12.

\section{LEAKage Magnetic FiELd OF RC-COUPLER}

In this section, finite element analysis tool is used to visualize and compare the magnetic field difference between different multiple output solutions. Three different models are built in Ansys Maxwell, the big transmitter coil in Fig. 1(a), the coil arrays with all coil activated in Fig. 1(b) and the RC-Coupler in this paper. For simplicity, multi-turn torus is used to replace the spiral coil. The big coil has three turns with radius of $300 \mathrm{~mm}$, $200 \mathrm{~mm}$ and $100 \mathrm{~mm}$ for each turn. The small coil in the coil arrays has 5 turns with radius be $85 \mathrm{~mm}, 79 \mathrm{~mm}, 73 \mathrm{~mm}, 67 \mathrm{~mm}$ and $61 \mathrm{~mm}$. the diameter of the RC-Coupler is the same as the coil array, but only one of the coils is excited with current. An RMS current of $2 \mathrm{~A}$, which equivalents to one receiver charging at rated power, at $6.78 \mathrm{MHz}$ is set as excitation for all the three models. The Fig. 13 shows the simulated magnetic field distribution around each case.

The safety limit of magnetic field density is $27 \mu \mathrm{T}$ [25]. Therefore, $27 \mu \mathrm{T}$ is set as the upper limit of the magnetic field plot and therefore the red region in simulation result indicate that the magnetic field strength is higher that $27 \mu \mathrm{T}$. From the simulation result, the unsafe region of big coil is a cylinder with $330 \mathrm{~mm}$ diameter and $80 \mathrm{~mm}$ height. For coil array, this region is also around all transmitter coils with a $270 \mathrm{~mm}$ diameter and $90 \mathrm{~mm}$ height. For the RC-Coupler, the region is reduced to $100 \mathrm{~mm} \times 90 \mathrm{~mm}$.

\section{EXPERIMENTAL VERIFICATION}

\section{A. Experiment setup}

To further evaluate the performance of the proposed RCCoupler, a prototype has been built and tested as shown in Fig. 14. The test setup includes a GaN based half-bridge inverter, an auxiliary power supply, three RC-Couplers and three receivers (laptop). The specifications of the system are listed in Table III.

The RC-Coupler, shown in Fig. 3(a), is under the computer with a size equal to the bottom area of the laptop. The capacitor plates are formed by the copper layer of PCB. At receiver side, a full bridge Schottky diode rectifier, a Buck DC/DC converter and a EMI filter is designed for each receiver devices and the output voltage are regulated to $20 \mathrm{~V}$ to adapt to the charging 


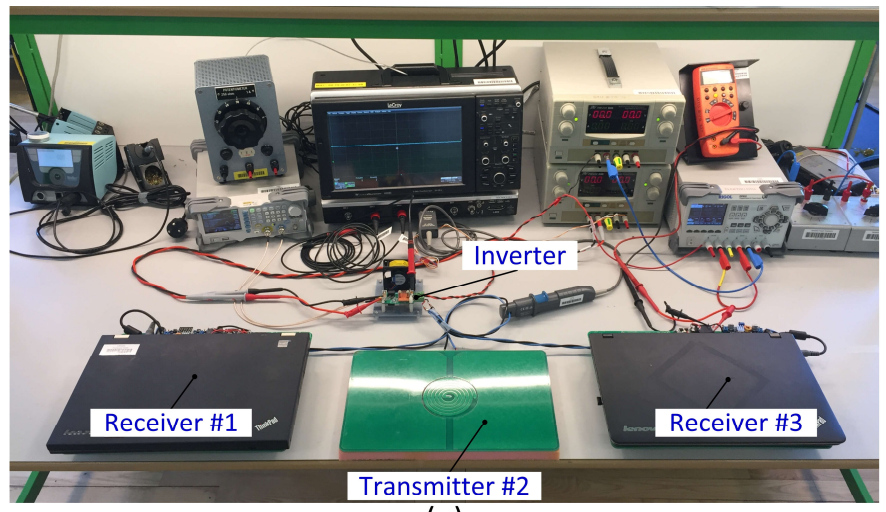

(a)
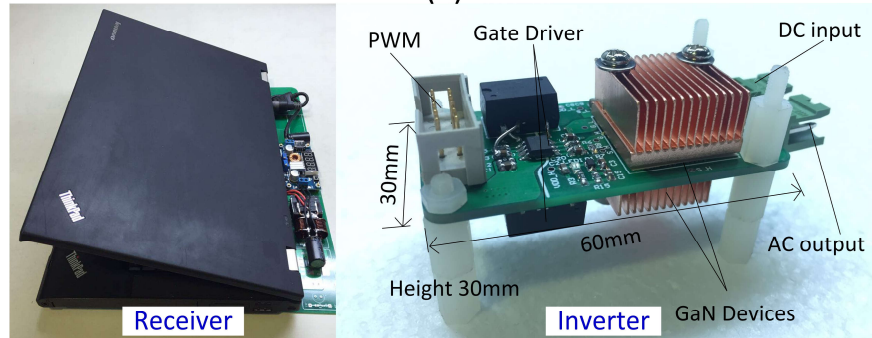

(b)

Fig. 14. Prototype of multiple output wireless power transfer system using RC-Coupler, (a) System setup, (b) Details of receiver and inverter.

TABLE V

SySTEM SPECIFICATIONS AND CiRCUIT PARAMETERS

\begin{tabular}{cccc}
\hline \hline Symbol & Value & Symbol & Value \\
\hline$V_{\text {in }}$ & $75 \mathrm{~V}$ & $C_{\mathrm{pp}}$ & $610 \mathrm{pF}$ \\
$V_{\text {out }}$ & $20 \mathrm{~V}$ & $C_{\mathrm{s}}$ & $610 \mathrm{pF}$ \\
$f_{\mathrm{sw}}$ & $6.78 \mathrm{MHz}$ & $L_{\mathrm{s}}$ & $1.087 \mu \mathrm{H}$ \\
$P_{\mathrm{o}}$ & $40 \mathrm{~W} \times 3$ & $\mathrm{GaN}$ & $\mathrm{GS} 66516 \mathrm{~T}$ \\
$L_{\mathrm{p}}$ & $1.087 \mu \mathrm{H}$ & Rectifier diode & VSSC8L45 \\
\hline \hline
\end{tabular}

requirement of laptop. At primary side, a GaN half-bridge is designed as primary inverter shown in Fig. 14(b). The size of the inverter is $6 \mathrm{~cm} \times 3 \mathrm{~cm} \times 3 \mathrm{~cm}$ and the two GaN devices are mounted at the same position but on both sides of the PCB board to minimize the stray inductance. With the RC-Coupler, the bidirectional switches in [16] are avoided and the power density of the inverter is increased to $2.78 \mathrm{~W} / \mathrm{cm}^{3}$

\section{B. Steady state performance}

Fig. 15 gives the measured waveforms of one receiver at steady state and rated power. As only one receiver is covered, the inverter current is the same as the coil current. According to the gain curve of Fig. 10, the output voltage can be regulated by adjusting the switching frequency. The gain as well as the output voltage will increase when switching frequency comes close to the resonant frequency.

Fig. 16 shows the measured inverter and coil currents with one, two and three receivers. The RMS currents for each receiver are around $2 \mathrm{~A}$. When a receiver is moved away from corresponding transmitter coil, the transmitter coil is deactivated and the current in that coil becomes zero as expected. The inverter current is the sum of three transmitter coils and it decrease as the receiver number decreases.

To confirm the reduction in magnetic field, measurement of

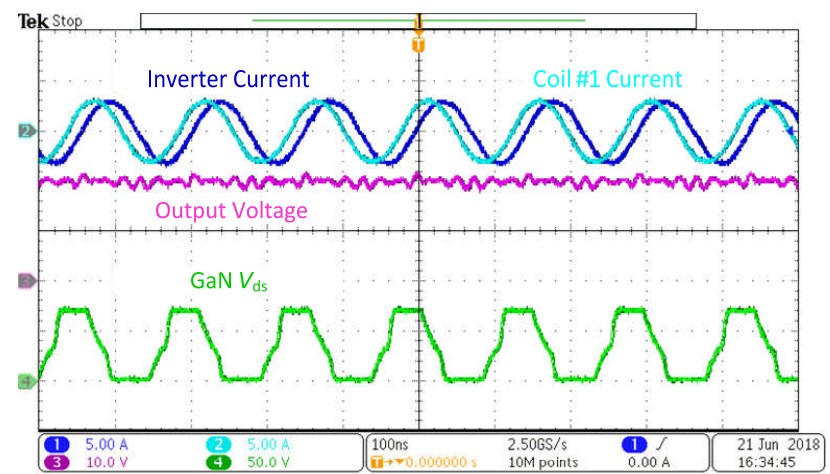

Fig. 15. Measured steady state waveforms of one receiver at rated power.

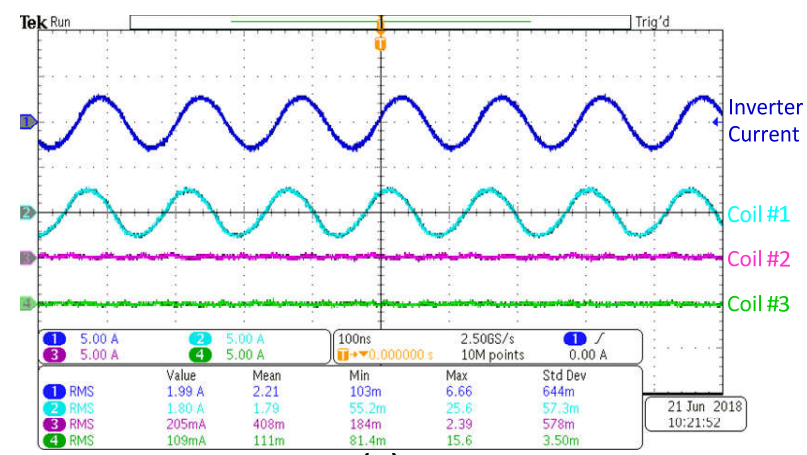

(a)

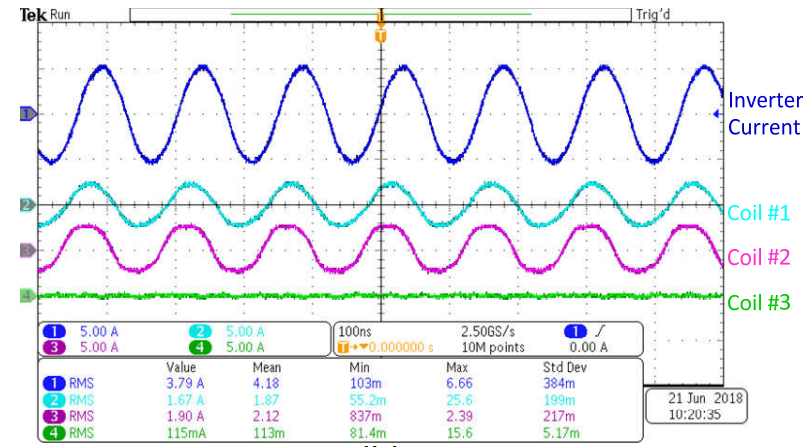

(b)

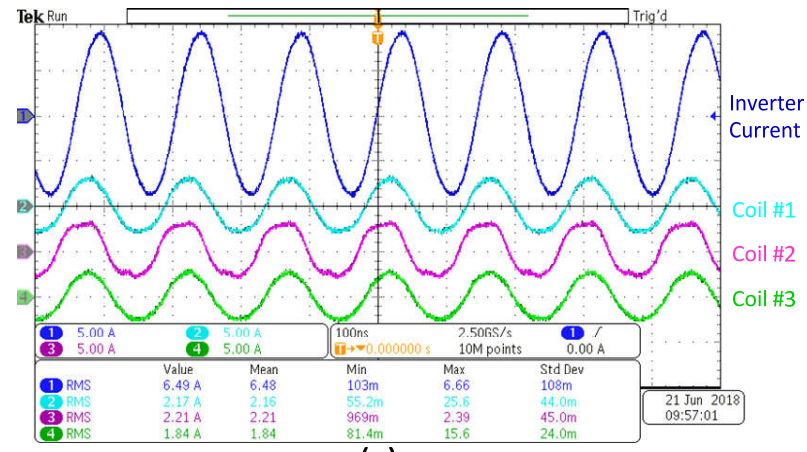

(c)

Fig. 16. Measured inverter and coil currents with one, two and three magnetic flux density along the surface of uncovered transmitter coils is conducted. A high frequency magnetic probe from Rohde \& Schwarz (RS H400-1) is used to measure the magnetic flux density around the uncovered transmitter coil. The probe is moved along the coil surface with different direction to measure the horizontal as well as vertical leakage 


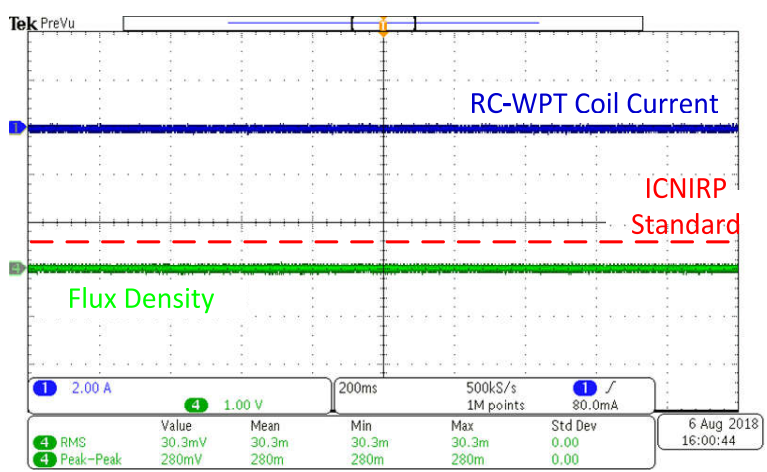

(a)

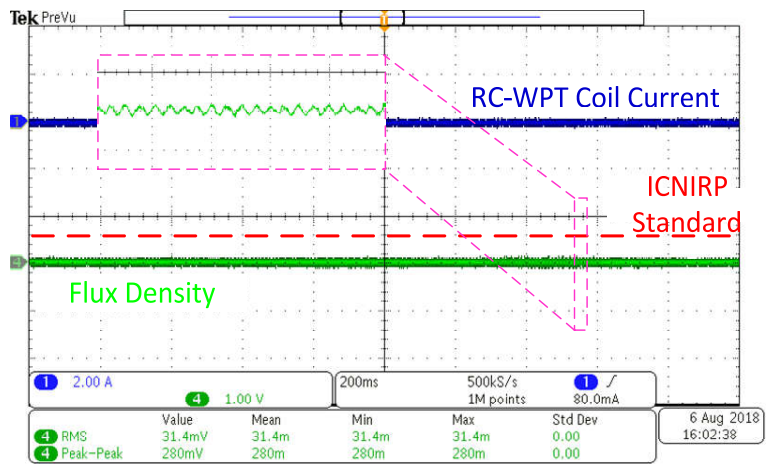

(b)

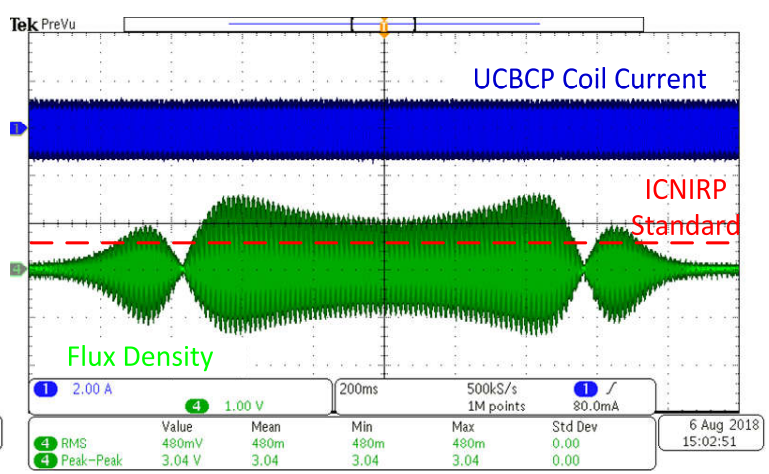

(c)

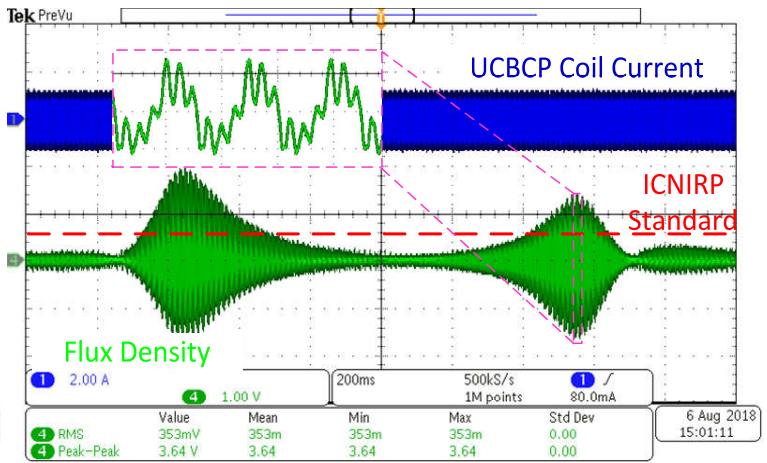

(d)

Fig. 17. Measured magnetic flux density along the uncovered transmitter coil surface. (a) RC-Coupler, vertical field, (b) RC-Coupler, horizontal field; (c) UCBCP, vertical field, (d) UCBCP, horizontal field.

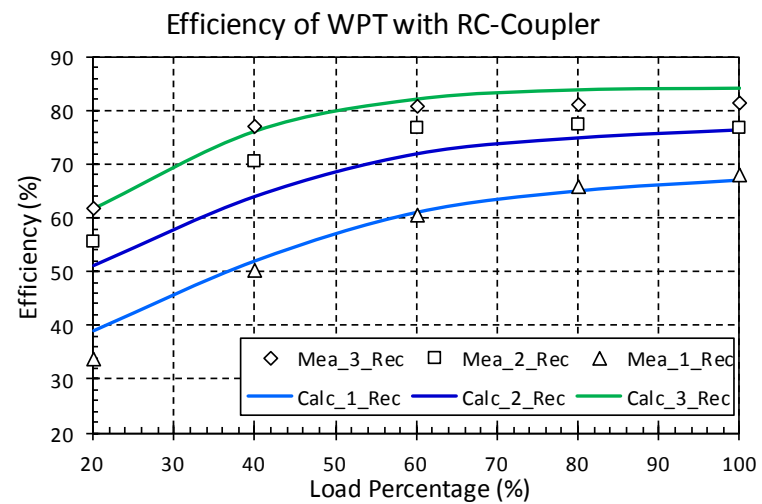

Fig. 18. Efficiency of RC-Coupler with different receivers.

magnetic fields generated by transmitter coil. The measurement result is shown in Fig. 17. For reference, the magnetic field of uncovered UCBCP coils with the same output power is also measured [26]. The ICNIRP standard is marked as the dashed line in Fig. 17. It can be observed that the leakage magnetic field of RC-Coupler is almost the same as the background field, which agrees with the design and simulation result. However, an obvious magnetic field around UCBCP coil is observed, which is higher than the ICNIRP standard.

Fig. 18 shows the measured efficiency of the prototype with different receivers and load percentages. The peak efficiency is $81.42 \%$ for three receivers at rated power (120W output with $40 \mathrm{~W}$ for each receiver). The system efficiency decreases from heavy load to light load, the lowest efficiency is $\sim 60 \%$ at $20 \%$ load. When the number of receivers decrease, the system efficiency decreases accordingly. The peak efficiency is $76.75 \%$ for two receivers and $68.20 \%$ for one receiver. The measured efficiency trends agree with calculated results with a tiny difference, which is caused by the parasitic parameters of active devices. The switching loss of the primary inverter is the main causes of the relative low efficiency when there is only one receiver. The coil current is not enough to discharge the output capacitors of GaN devices before it is switched on, which can be observed from $V_{\text {ds }}$ curve in Fig. 15. The inverter is not in ZCS state when output power is lower than the $30 \%$ of the rated power.

\section{Misalignment Performance}

The misalignment performance of a wireless power transfer system is very important because the receiver cannot always be well aligned to the transmitter. Therefore, the misalignment performance of the proposed RC-Coupler is evaluated. As benchmark, the misalignment performance of classical seriesseries (SS) compensated inductive power transfer topology is also measured and plotted together as shown in Fig. 19. The only difference between the RC-Coupler and benchmark SScompensation is the primary resonant capacitor. For RCCoupler, this resonant capacitor is formed by separable parallel plate capacitor as described in section II, and for SScompensation, this resonant capacitor is replaced by film capacitor with the same capacitance.

The out radius of the coil is $4.25 \mathrm{~cm}$, the misalignment is measured from $0 \mathrm{~cm}$ to $3.5 \mathrm{~cm}$ with a step of $0.5 \mathrm{~cm}$. Since the designed output power is $40 \mathrm{~W}$, two output power cases are 


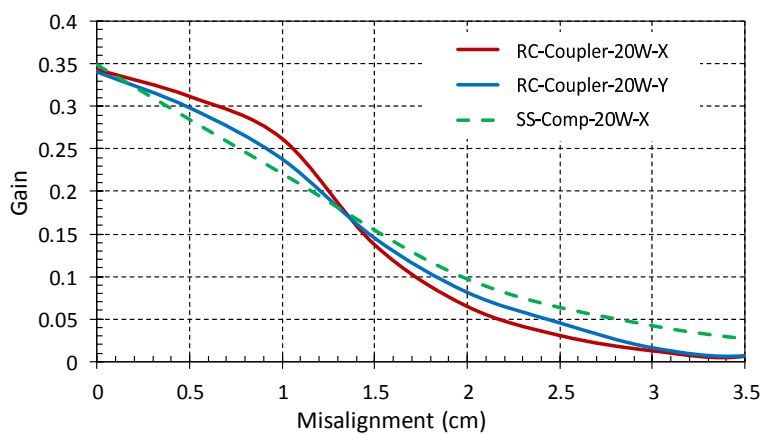

(a)

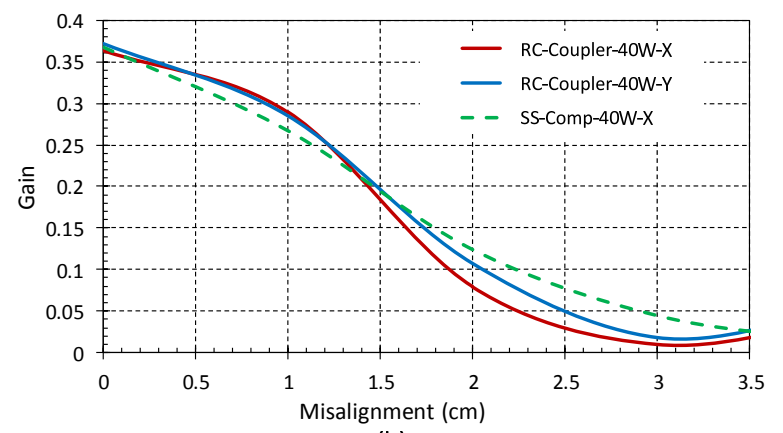

(b)

Fig. 19. Measured Gain with different output power and misalignment, (a) $20 \mathrm{~W}$ output, and (b) $40 \mathrm{~W}$ output.

chosen, 20W (half power) and 40W (full power). For SScompensation, since the coil is axisymmetric, only the misalignment along $x$ axis is measured. For the RC-Coupler, both $x$ and $y$ axis misalignment are measured. From Fig. 19, the gain of both SS-compensation and RC-Coupler decrease as misalignment happens. However, for misalignment lower than $1.4 \mathrm{~cm}$ ( $33 \%$ of the out radius), the gain of RC-Coupler keeps higher than SS-compensation. The gain curves show an intersection point at $33 \%$ misalignment, and after that, the gain of RC-Coupler becomes lower than the SS-compensation. Both $20 \mathrm{~W}$ case and $40 \mathrm{~W}$ case show the same feature. This means that the proposed RC-Coupler has better misalignment performance when misalignment is less than $33 \%$ of the out radius of the coil and becomes worse when misalignment becomes larger.

This can be explained as follows. The primary side resonant frequency is determined by the primary resonant capacitor and leakage inductor as described in Eq. (11). For SS-compensation, the $C_{\mathrm{pp}}$ is constant and $L_{\mathrm{p}}$ increase as misalignment happens. This leads to a decrease of resonant frequency $f_{\mathrm{p}}$. As shown in Fig. 20, when resonant frequency decrease and inverter frequency is constant at $6.78 \mathrm{MHz}$, the gain of the SScompensation decrease as the difference between resonant frequency and switching frequency becomes larger. For RCCoupler, the decrease of resonant frequency will also cause a difference between resonant frequency and switching frequency and further cause gain decrease. However, a good thing for RC-Coupler is that the primary resonant capacitor $C_{\mathrm{pp}}$ is not constant anymore. The $C_{\mathrm{pp}}$ decrease with misalignment because the overlapped area between $\mathrm{P}_{1}, \mathrm{P}_{2}$ and $\mathrm{P}_{3}$ in Fig. 3 decreases. According to the experiment result in Fig. 19, when misalignment is less than $1.4 \mathrm{~cm}$, the decrease of $C_{\mathrm{pp}}$

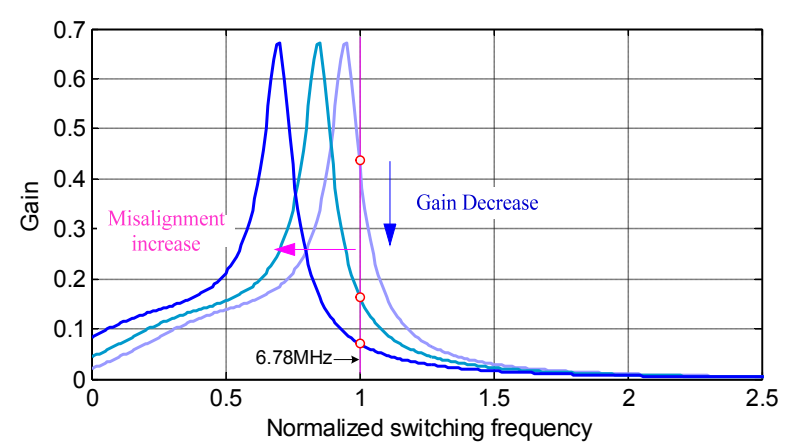

Fig. 20. Gain variation with resonant frequency.

compensates the increase of $L_{\mathrm{p}}$ and makes the resonant frequency decreases slower than the SS-compensation.

\section{CONCLUSION}

The concept of receiver controlled wireless power transfer as well as a novel receiver-controlled coupler (RC-Coupler) to realize multiple output wireless charging platform is proposed in this paper. The key idea of the RC-Coupler is taking advantage of the large bottom area of receiver to construct two separable capacitors that serve as both primary side resonant components and receiver-controlled switches. The RC-Coupler realized a unique feature that only those transmitter coils covered by receiver devices are activated. Two benefits are obtained by using the proposed concept and RC-Coupler. First, the leakage magnetic field is minimized to only around the specific transmitter coil that is transferring power. Second, the conventional active bidirectional switches as well as sensors and driving circuits are saved, which lowers the system cost and complexity and increases the power density of primary circuits. A $6.78 \mathrm{MHz}, \mathrm{GaN}$ based inverter with a power density of $2.78 \mathrm{~W} / \mathrm{cm}^{3}$ is designed and demonstrated. The operation principle as well as design considerations of the proposed RCCoupler is given and validated with both simulation and experiment results. The experiment results show that the separable capacitance and the proposed topology can realize receiver controlled wireless power transfer with a system efficiency of $81.42 \%$ for three receivers. The proposed RCCoupler can be used for wireless power transfer in MRI equipment.

\section{REFERENCES}

[1] R. Bosshard, J. W. Kolar, "Multi-objective Optimization of $50 \mathrm{~kW} / 85$ kHz IPT System for Public Transport," IEEE J. Emerg. Sel. Topics Power Electron. vol. 4, no. 4, pp. 1370-1382. Dec. 2015.

[2] L. Pugi, A. Reatti, F. Corti, "Application of Wireless Power Transfer to Railway Parking Functionality: Preliminary Design Considerations with Series-Series and LCC Topologies," Journal of Advanced Transportation, vol. 2018, pp. 1-15. Dec. 2018

[3] G. Jung, B. Song, S. Shin, S. Lee, J. Shin, Y. Kim, S. Jeon, "High Efficient Inductive Power Supply and Pickup system for On-Line Electric Bus," in Proc. IEEE EVC, pp.1-5, 2012.

[4] R. F. Xue, K. W. Cheng, and M. Je, "High-efficiency wireless power transfer for biomedical implants by optimal resonant load transformation," 
IEEE Trans. Circuits Syst. I, Reg. Papers, vol. 60, no. 4, pp. 867-874, Apr. 2013.

[5] G. Wang, W. Liu, M. Sivaprakasam, G.A. Kendir, "Design and Analysis of An Adaptive Transcutaneous Power Telemetry for Biomedical Implants," IEEE Trans Circuits Syst. I: Regular Papers., vol. 52, no. 10, pp. 2109-2117, Oct. 2005.

[6] M. Ghovanloo and K. Najafi, "A Wideband Frequency-Shift Keying Wireless Link for Inductively Powered Biomedical Implants," IEEE Trans. Circuits and Systems - I, vol. 51, no. 12, pp. 2374-2383, Dec. 2004

[7] S. Y. Hui, "Planar Wireless Charging Technology for Portable Electronic Products and Qi," Proceedings of the IEEE, vol. 101, no. 6, pp. 1290-1301. Jun. 2013.

[8] E. Bou-Balust, A. P. Hu, and E. Alarcon, "Scalability analysis of SIMO non-radiative resonant wireless power transfer systems based on circuit models," IEEE Trans. Circuits Syst. I, Reg. Papers, vol. 62, no. 10, pp. 2574-2583, Oct. 2015.

[9] [Online]. Available: http://epc-co.com/epc/GaNTalk/Post/14326/Nobody -Likes-Power-Cords-Wireless-Power-is-Happening.aspx.

[10] J. T. Boys, G. A. Covic, "The Inductive Power Transfer Story at the University of Auckland," Circuits \& Systems Magazine IEEE., vol. 15, no. 2, pp. 6-27, May. 2015.

[11] J. Kim, D. H. Kim, Y. J. Park, "Analysis of capacitive impedance matching networks for simultaneous wireless power transfer to multiple devices," IEEE Trans Industrial Electron., vol. 62, no. 5, pp. 2807-2813. May. 2015.

[12] S. Y. R. Hui, W. W. C. Ho, "A New Generation of Universal Contactless Battery Charging Platform for Portable Consumer Electronic Equipment," IEEE Trans. Power Electron., vol. 20, no. 3, pp. 620-627, May. 2005.

[13] X. Liu, S. Y. R. Hui, "Equivalent Circuit Modeling of a Multilayer Planar Winding Array Structure for Use in a Universal Contactless Battery Charging Platform," IEEE Trans. Power Electron., vol. 22, no. 1, pp. 2129, Jan. 2007.

[14] K. Horigome, F. Koshiji, and K. Koshiji, "Comparison of wireless power transmission characteristics using circular-coil array and elliptical coil as a transmission coil," in Int. Conf. Electron. Packag., pp. 811-814, Apr. 23,2014

[15] W. X. Zhong, X. Liu, S. Y. R. Hui, “A Novel Single-Layer Winding Array and Receiver Coil Structure for Contactless Battery Charging Systems with Free-Positioning and Localized Charging Features," IEEE Trans. Ind. Electron., vol. 58, no. 9, pp. 4136-4144, Sept. 2011.

[16] K. Bryon, F. Robb, S. Vasanawala, J. Pauly, G, Scott, "A Wireless Power Transfer System for MRI Scanners," in Proc. IEEE WPTC, PP. 1-4, 2018.

[17] A. E. Umenei, J. Schwannecke, S. Velpula, "Novel Method for Selective Nonlinear Flux Guide Switching for Contactless Inductive Power Transfer," IEEE Trans. Magnetics., vol. 48, no. 7, pp. 2192-2195, Jul. 2012.

[18] J. Dai, D. C. Ludois, "A survey of wireless power transfer and a critical comparison of inductive and capacitive coupling for small gap applications," IEEE Trans. Power Electron., vol. 30, no. 11, pp. 60176029, Nov. 2015

[19] Y. H. Kim, H. Lee, O. Lee, J. Kim, S. Bang, "Dielectric characteristics of solid insulation materials with respect to surface roughness," IEEE Trans. Appl. Supercond., vol. 23, no. 3, Jun. 2015.

[20] [Online]. Available: https://www.airfuel.org/.

[21] C. Liu, Y. Zhang, and X. Liu, "Circularly polarized implantable antenna for $915 \mathrm{MHz}$ ISM-band far-field wireless power transmission," IEEE Antennas Wireless Propag. Lett., vol. 17, no. 3, pp. 373-376, Mar. 2018.

[22] S. S. Mohan, M. H. M. Del, S. P. Boyd, T. H. Lee, "Simple Accurate Expressions for Planar Spiral Inductances," IEEE J. Solid-State Circuits., vol.34, no.10, pp. 1419-1424, Oct. 1999.

[23] M. Kiani, M. Ghovanloo, "A Figure-of-Merit for Designing HighPerformance Inductive Power Transmission Links,” [J]. IEEE Trans. Ind. Electron., vol.60, no.11, pp. 5292-5305, Nov. 2013.

[24] Y. Zhang, Z. Zhao, K. Chen. "Frequency Decrease Analysis of Resonant Wireless Power Transfer," IEEE Trans. Power Electron., vol.29, no.3, pp.1058-1063, Mar. 2013.
[25] IEEE Standard for Safety Levels with Respect to Human Exposure to Radio Frequency Electromagnetic Fields, $3 \mathrm{kHz}$ to $300 \mathrm{GHz}$, IEEE Standard C95.1, 2005.

[26] International Commission on Non-Ionizing Radiation Protection, "guidelines for limiting exposure to time-varying electric, magnetic and electromagnetic fields (1 Hz to $100 \mathrm{kHz}$ )," Health Phys., vol. 99, pp. 818$836,2010$.

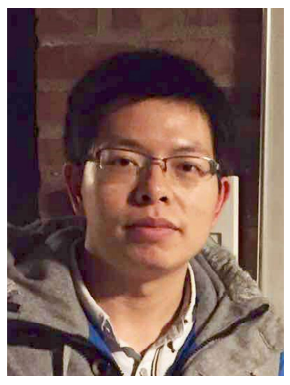

Xu Chen (S'15) received the B.Sc. degree in electrical engineering from Jilin University, Changchun, China, in 2014. He is currently working toward the Ph.D. degree in power electronics at Jilin University, Changchun, China. He was an intern at ABB (China) Ltd., Cooperate Research Center from July 2015 to July 2018. Since October 2018, he has been sponsored by the China Scholarship Council to study as a visiting $\mathrm{PhD}$ student at the Department of Electrical Engineering, Technical University of Denmark, Lyngby, Denmark. His research interests include wireless power transfer, grid-connected photovoltaic inverter, and reliability of power electronics.

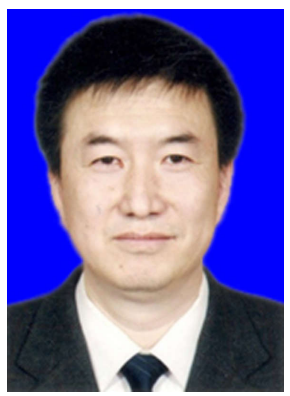

Shengbao Yu received the B. E. degree in wireless communication technology from Dalian University of Technology, Dalian, China, in 1985, M. S. degree in electronic instrumentation from Russia's Far-east State Technical University, Vladivostok, Russia, in 2000, and Ph.D. degree in instrument science and technology from Jilin University, Changchun, China, in 2007. He is currently a professor and leader of power electrics group in the College of Instrumentation and Electrical Engineering, Jilin University. He holds 18 patents in geophysical detection instrument and special power supply, published more than 30 peer reviewed journal and conference papers. Dr. Yu received the "National Technology Invention Award" twice and the first prize of "Science and Technology Invention of Ministry of Education". His research interests include special power supply, geophysical detection instrument, and wireless power transfer.

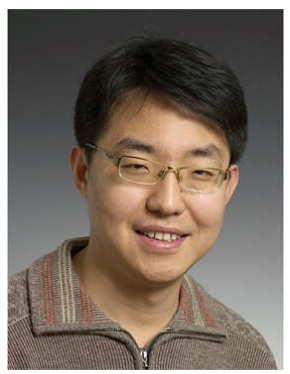

Zhe Zhang (M'11-SM'16) received the B.Sc. and M.Sc. degrees in power electronics from Yanshan University, Qinhuangdao, China, in 2002 and 2005, respectively, and the $\mathrm{PhD}$ degree from the Technical University of Denmark, Kgs. Lyngby, Denmark, in 2010.

$\mathrm{He}$ is currently an Associate Professor in the Department of Electrical Engineering, at the Technical University of Denmark (DTU). Since Jan. 2018, he has been Head of Studies, Electrical Engineering MSc Programme. From 2005 to 2007, he was an Assistant Professor at Yanshan University. From June 2010 to August 2010, he was with the University of California, Irvine, CA, USA, as a visiting scholar. He was an Assistant Professor at the Technical University of Denmark during 2011 and 2014. He has authored or co-authored more than 150 transactions and international conference papers and filed over ten patent applications.

Dr. Zhang's current research interests include applications of wide bandgap devices, wireless power transfer, high frequency dc-dc converters, multipleinput dc-dc converters, soft-switching power converters and multi-level dc-ac inverters for renewable energy systems (RES) and hybrid electric vehicles (HEV). 